\title{
Assessment and Adoption of Tomato Charcoal Cooler Storage Bin for Farmers in The Tropics
}

\author{
Chukwuemeka Jude Ohagwu ${ }^{1 *}$, Violet Amarachukwu Ohagwu ${ }^{2}$, Joel Nwaeze Nwakaire ${ }^{3}$ \\ ${ }^{1,3}$ Department of Agricultural and Bioresources Engineering, University of Nigeria, Nsukka \\ ${ }^{2}$ Department of Agricultural Extension, University of Nigeria, Nsukka \\ *Corresponding author: Chukwuemeka Jude Ohagwu, Email: chukwuemeka.ohagwu@unn.edu.ng
}

Submission: February 20, 2020; Revision: April 10, 2020; Acceptance: April 27, 2020

\begin{abstract}
The study tends to study the postharvest technological evaluation of different tomato storage environments/media for domestic preservation of fresh and fleshy tomato quality to improve its shelf life with emphasis on charcoal cooler storage bin (CCB). It involved the preliminary investigation of farmers' knowledge and skill with regard to tomato preservation and storage with different tomato storage environments, adoption of developed CCB: design capacity was $40 \mathrm{~kg} /$ batch storage for 7 days in Nsukka. These were conducted between April to September, 2019. The field studies were carried out through structured questionnaire to know the adaptive knowledge and skill of farmers with regard to tomato preservation and storage. Comparative study of the developed CCB with other environmental storage conditions namely: open-air (ambient) storage (OAS), refrigerator (RF), freezer (FR), (room) laboratory storage (LS), and thatched house storage (THS) were carried out. The four varieties of fresh and fleshy harvested tomato fruits: Copra, Nindo F1, Yolings, and UTC locally cultivated were set into the 6 treatments (media), each treatment was replicated twice. The study showed that the quality attributes such as cracking, yellowing, weight loss, rottening, hardness, and brix value were determined. Based on the physicomechanical parameters of the tomatoes under seven days investigation, $\mathrm{FR}\left(0^{\circ} \mathrm{C}, 95 \%\right)$ and $\mathrm{RF}\left(10{ }^{\circ} \mathrm{C}, 85 \%\right)$ had better quality and prolonged shelf life, followed closely by the tomato CCB storage $\left(12{ }^{\circ} \mathrm{C}, 85 \%\right)$ and THS $(12$ $\left.{ }^{\circ} \mathrm{C}, 78 \%\right)$ then $\mathrm{LS}\left(25^{\circ} \mathrm{C}, 78 \%\right)$ and $\mathrm{OAS}\left(30^{\circ} \mathrm{C}, 78 \%\right)$. FR storage inhibited/delayed (cold stress) ripening with minimum weight loss, as compared to the other treatments in terms of stability in all parameters. Similarly, CCB was close to RF storage and performed significantly better than ambient OAS and LS. OAS and LS exhibited higher weight loss, and rapid ripening to deterioration due to tropical temperature and relative humidity fluctuation. Therefore, CCB is recommended for rural small scale farmers.
\end{abstract}

Keywords: Charcoal cooler storage bin; farmers' knowledge and skills; postharvest tomato storage environments; tomato varieties 


\section{INTRODUCTION}

Tomato (Solanum lycopersicum) is an essential fruit vegetable that is cultivated and consumed in processed form worldwide. It serves as a source of nutrients and minerals with many health-related benefits to the human body. Furthermore, with the inherent benefits and globally acceptance across societies, tomato production could improve the livelihood of farmers through job creations and also act as a major source of income for rural and semi-urban dwellers (Arah et al., 2015). In tropical countries of Africa, tomatoes are grown in both wet and dry seasons, and this allows it offer lots of economic benefits worldwide (Arah et al., 2016). High demand for fresh tomatoes as staple vegetables created a frontier for its production with the intention of being readily available and also serve as feedstock for tomato processing industries. However, postharvest storage of these fruits was the major cause of seasonal fluctuation in availability, deterioration in quality and other socio-economic inadequacies due to the fact that an efficient means of storage other than canning is yet to be developed (FAO, 2010). Ultimately, the inherent medicinal and nutritional values of this fruit were utilized through consumption of the fresh and fleshy parts. Therefore, maximizing the enormous benefits of tomato production entails solving problems of postharvest handling and storage in preserving and maintaining its quality and shelf life. Fresh produce continues to loose water after harvest depending on the varieties, while the mature ones immediately deteriorates. Water loss causes shrinkage and loss of weight. Therefore, in order to extend the shelf or storage life, the rate of water loss need to be minimal (FAO, 2008). At large scale, vegetable preservation is very difficult in the tropics due to poor transportation systems and high environmental temperatures that encourages decay rather than storage. Furthermore, the challenges of sub-Sahara African nations over tomato production were based on how to preserve fresh vegetable produce in order to feed an ever increasing population (FAO, 2013). Meanwhile, very little information exists on the benefits and options of preservative temperature suitable for tomato storage and also for existing small-scale preservative conditions. This problem could be surmounted through environmental control and monitoring of the storage/ preservation environment as well as exploring for better appropriate technology that would solve the problem of vegetable storage and guarantee its quality and shelf life. In order to provide solutions regarding tomato preservation vis a vis quality, shelf life and availability of fresh tomatoes for consumption requires substantial motivation. Furthermore, this technology (charcoal cooler storage bin) is economical, does not require electricity and could preserve fresh tomatoes for short term based on cool air using less energy resulting from evaporation than refrigeration since charcoal bin resist heat conduction. Therefore, the study involved the preliminary investigation of different tomato storage environments with regards to the knowledge and skills of farmers, development of charcoal cooler tomato storage bin, and experimental studies in Nsukka (tropical environmental conditions, namely temperature and relative humidity). Furthermore, the objectives involved carrying out studies on tomato farmers' postharvest knowledge and skills in order to investigate their capabilities on tomato preservation and storage, also to design, construct and carry out performance evaluation of charcoal cooler tomato storage bin. Finally, to investigate six storage conditions for tomato preservation and storage in Nsukka and to give recommendations based on the findings.

\section{MATERIALS AND METHODS}

The research investigations were segmented into three steps, first field study through the administration of structured questionnaire. This contains preliminary personal data of farmers and their postharvest knowledge and skills in order to investigate their capabilities on tomato preservation. These were distributed to farmers within Enugu north senatorial zone which comprises six local government namely Nsukka, Igboeze south and north, Udenu, Igbo etitti, and Uzouwani local government areas in Enugu State, Nigeria. Tomato farmers within these areas were located and the instrument was distributed, collated, and processed with the aid of excel worksheets. The second step involved the design, construction, and performance of charcoal cooler tomato storage bin. The design consists of an evaporative cooling mechanism of charcoal, two storage trays of $40 \mathrm{~kg} / \mathrm{batch}$ and sides filled with activated charcoal. Furthermore, the materials used for construction were sourced locally.

\section{Material}

These include tools such as hammer, saw, wire cutter and scissors, drilling machine, iron handle, welding machine and gluten cutting machine, and also materials such as wood board (1 piece, approximately $30.48 \mathrm{~cm} \times 30.48 \mathrm{~cm}$ ) dimensions of the base of the cooler, 2 hinges, perforating glass, basket, bolts, and nuts, charcoal (approximately $4 \mathrm{~kg}$ ), nails or a staple gun with staples, cloth (Jute cloth or canvas, approximately $365.76 \mathrm{~cm}$ was required), wire mesh (approximately 10 
$\mathrm{m}^{2}$ was required), wood $(356.76 \times 1 \mathrm{~cm} \times 2 \mathrm{~cm})$ and water. The third step was to evaluate different tomato storage environmental studies and six postharvest storage environment with their storage conditions.

\section{Equipment}

The equipments used were freezer $\left(0^{\circ} \mathrm{C}, 95 \%\right)$, thatched house $\left(12^{\circ} \mathrm{C}, 78 \%\right)$, laboratory $\left(25^{\circ} \mathrm{C}, 78 \%\right)$, open-air $\left(30^{\circ} \mathrm{C}, 78 \%\right)$ and refrigerator storages $\left(10^{\circ} \mathrm{C}\right.$, $85 \%)$, and charcoal cooler tomato storage bin $\left(12{ }^{\circ} \mathrm{C}\right.$, $85 \%)$. The experiment was conducted at the department of Agricultural and Bioresources Engineering, University of Nigeria, Nsukka between April and September, 2019. The fresh and flesh harvested tomato fruits were set into six treatments, each having 2 replications. Therefore, 48 experimental setups completely randomized (CR) (storage media/conditions) were examined using four tomato varieties, namely Copra, Nindo F1, Yolings, and UTC locally cultivated. Other instruments used were hydrometer, thermometer, digital camera, digital weighing balance, measuring can, refractometer and universal testing machine. Figure 1 shows the diagram of the developed charcoal cooler storage bin.

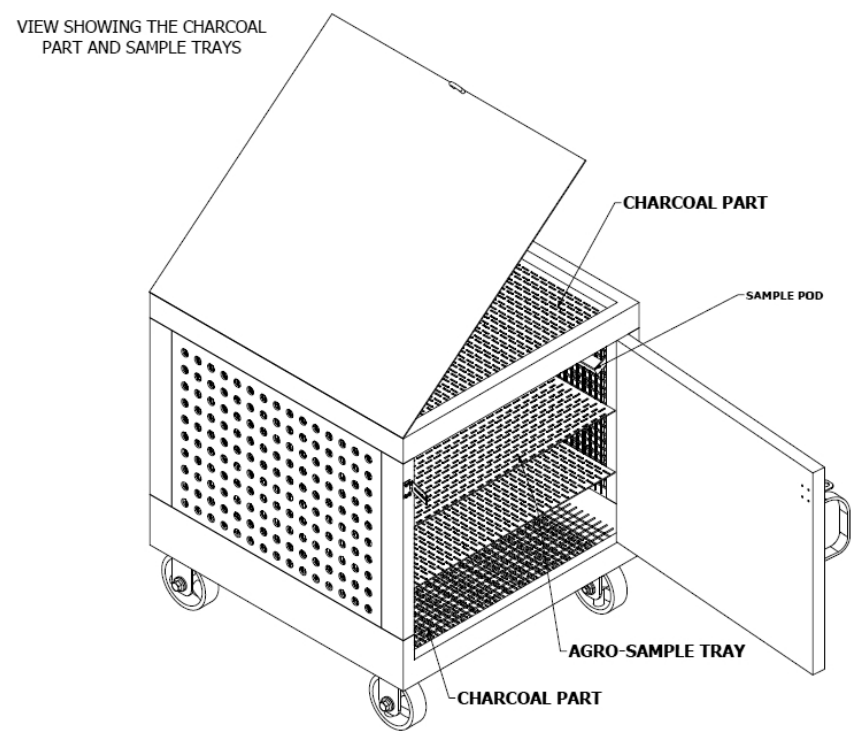

Figure 1. Developed tomato charcoal cooler bin

During the process of designing the system, it was taken into consideration that the system was passively under the influence of varying tropical weather condition by perforating the side walls of the storage bin and the one way cross ventilation after wetting the charcoal. Furthermore, opening of the charcoal chambers for wetting and filling, two trays (layers of stocking) of $40 \mathrm{~kg}$ capacity for the produce, and a shot door to minimize outside interference such as microclimatic conditions, pest and diseases. The design diagrams showing the views of the developed tomato charcoal cooler bin are shown in Figure 2 and 3 respectively as well as the autographic view of the system (Odesola and Onyekachi, 2009).

\section{Testing and Operation of the Developed Tomato Charcoal Cooler Storage Bin}

The cooler bin was tested without load by wetting the charcoal wall with water from top uniformly to the point of dripping, closed and allowed to settle for 30 minutes before readings were taken for bin temperature and ambient, and relative humidity. Furthermore, the rate of evaporation was determined using Equation (6).

\section{Principle of Tomato Charcoal Cooler Bin Storage}

The rate of evaporation on passive tomato charcoal cooler bin was referred to as the volumetric energy transmitted away from charcoal-water surface by the latent heat of water vapour in order to achieve the phase change of water to vapour (gas) with time. Furthermore, when water from moist/wetted charcoal surface changes to vapour when heated by the sun or increase in environmental heat change, it rises into the atmosphere and take the solar energy with it, resulting in a cooling effect. Therefore, the sensible volumetric enthalpy of the charcoal bin storage is given as

$H=\int_{t_{w}}^{t} \rho_{w} C_{w} d t, \quad t<t_{w} \quad$ wetting of charcoal

also at evaporative cooling, the enthalpy is given as

$H=\int_{t_{w}}^{t} \rho_{w} C_{w} d t+\rho_{w} L_{w}, \quad t<t_{w}$ vapour escape from the charcoal bin

Furthermore, the temperature at every stage of evaporative cooling is given as

$t=\frac{t_{w}+H}{\rho_{w} C_{w}}, \quad$ when $H<0$ (liquid) $\quad$ wet stage
$t=t_{w}, 0 \leq H \leq \rho_{w} L$ at interface $\quad t=t_{w}, 0 \leq H \leq \rho_{w} L$ at interface

$t=\frac{t_{w}+\left(H-\rho_{w} L\right)}{\rho_{w} C_{w}}, H>\rho_{w} L_{w} \quad$ gasous (vapour) stage

where, $\rho_{w} \rho_{w}=$ density of water, $C_{w} C_{w}=$ specific heat capacity of water, $t t=$ temperature of the air, $t_{w} t_{w}=$ temperature of water, $L L=$ Latent heat of vaporization, $2260 \mathrm{~kJ} / \mathrm{kg}, H H=$ Enthalpy

Evaporative cooling reduces the cooler bin and consequent air temperature through the latent heat absorbed during phase change from water. The rate of evaporation is given as: 


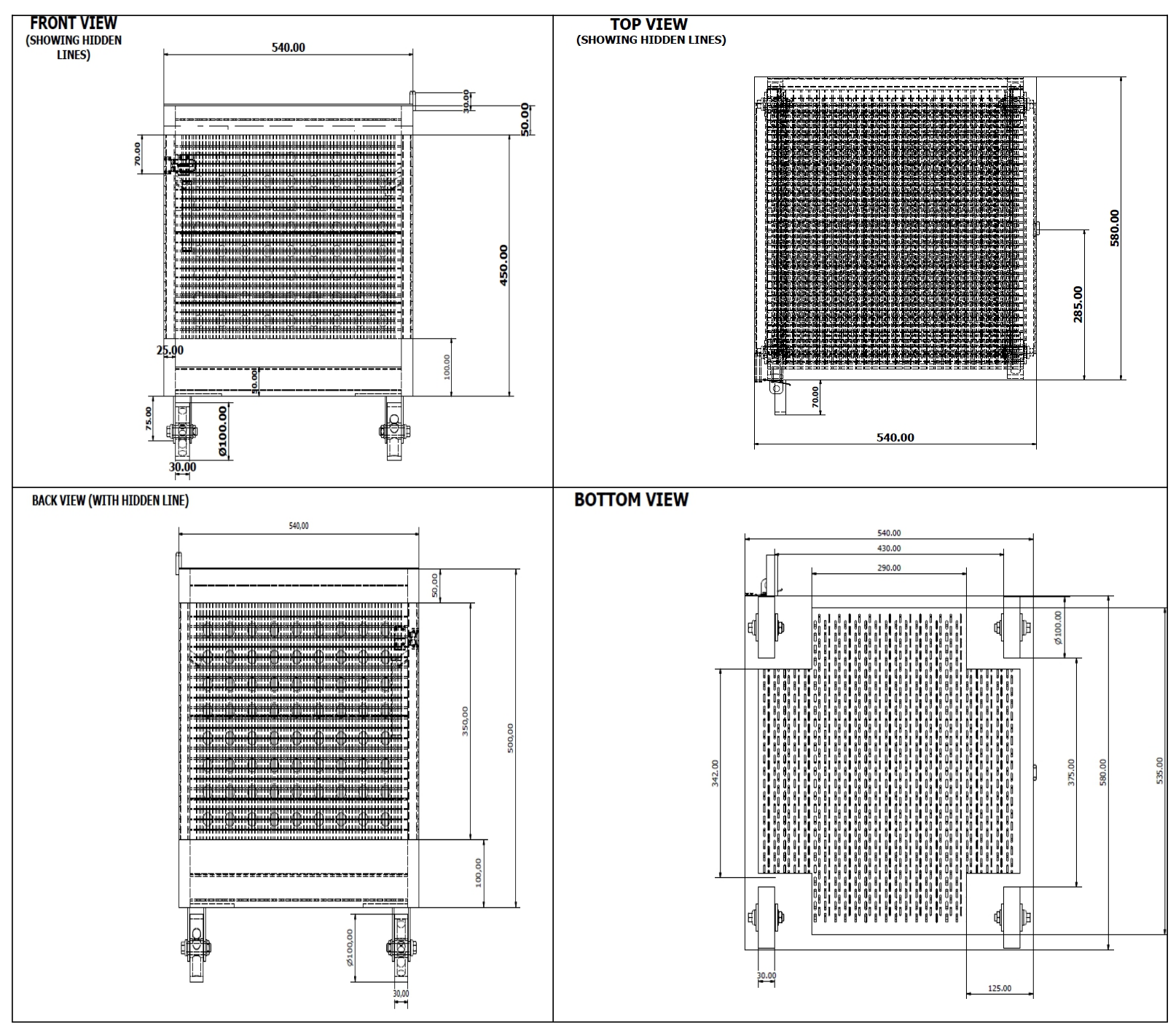

Figure 2. Showed different views of the designed tomato charcoal cooler storage bin

$E R=\frac{\left(M_{2}-M_{1}\right)}{\left[A\left(t_{2}-t_{1}\right)\right]}$

Then, the cooling effect is given as

$q_{\text {evap }}=L\left[\frac{\left(M_{2}-M_{1}\right)}{A\left(t_{2}-t_{1}\right)}\right]$

where, $M_{2} M_{2}=$ total mass $(\mathrm{kg})$ of charcoal and water at time (t), $M_{1} M_{1}=$ total mass $(\mathrm{kg})$ of charcoal and remaining water at time (t), $A A=$ Area of the charcoal bin, $t_{1} t_{1}=$ temperature of air, $t_{2} t_{2}=$ temperature of wetted charcoal, $q_{\text {evap }} q_{\text {evap }}=$ cooling effect $\left(\mathrm{kJ} / \mathrm{m}^{2} / \mathrm{h}\right)$.

The weather data (including air temperature, relative humidity, solar radiation, wind speed, rain, air pressure) were also monitored using a nearby weather station. This was carried out in order to establish the evaporative cooling effect before usage. After one hour, the rate of moisture escape was checked and wetted accordingly. Furthermore, early morning harvested flesh and fresh tomatoes of the above mentioned local varieties devoid of bruises, contaminants, or mechanical damage (preferably hand plucked) were used. Efforts were made to minimize handling and transportation and its effects were not considered. For the experiments, tomato stocking/load in the bin took place in the morning after harvesting. The average temperature and relative humidity of the bin were $12{ }^{\circ} \mathrm{C}$ and $85 \%$ for April to September, 2019 at the ambient range of 30 to $32{ }^{\circ} \mathrm{C}$.

\section{Experimental Set Up to Compare Different Storage Media/Conditions of Tomatoes}

Flesh and fresh tomato fruits were loaded into the storage bin, and at hour intervals readings were taken using instruments stated above. 


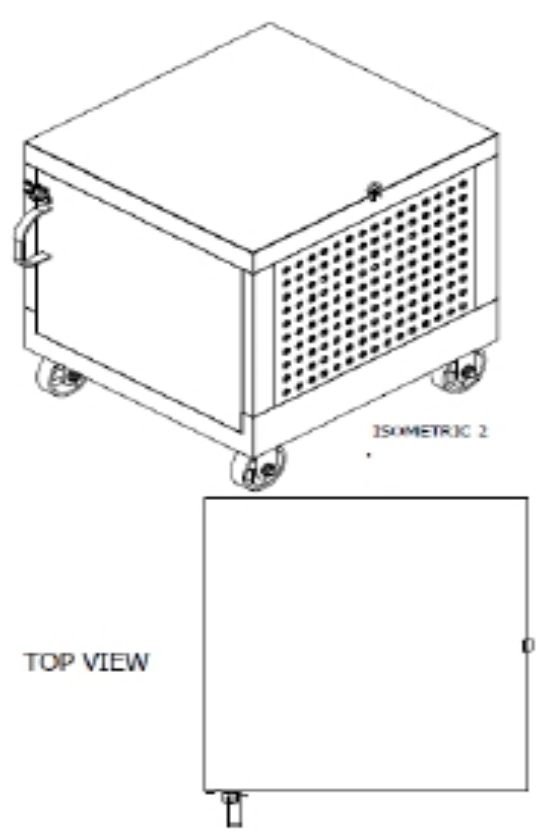

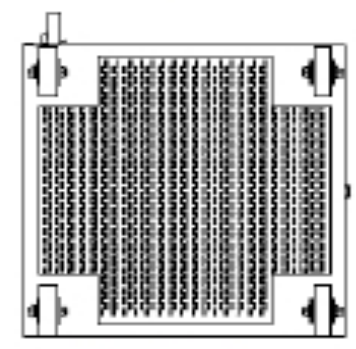

BOTTOM VIEW

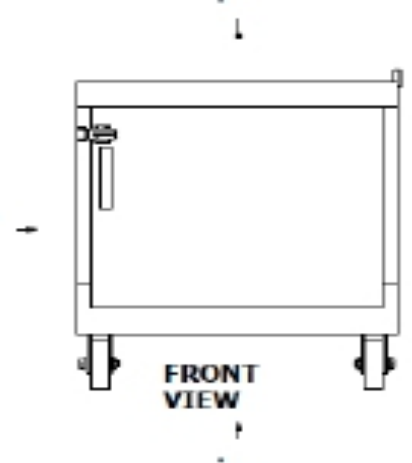

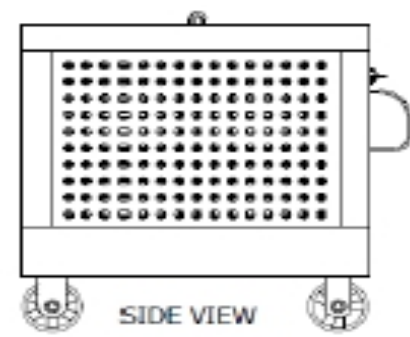

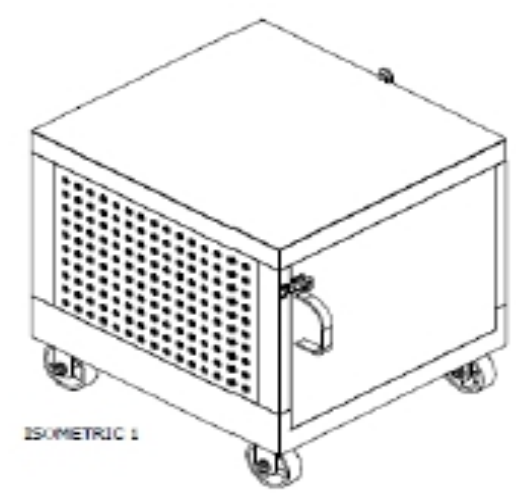

Figure 3. Showed autographic views of the designed tomato charcoal cooler storage bin

\section{RESULTS AND DISCUSSION}

Based on the methodology presented above, the farmers' response to the administered questionnaire were screened and data generated were for socio-economic characteristics of respondents. The parameters include:

\section{Sex}

Entries in Table 1 show that majority (67.5\%) of the respondents were females. This shows a female dominated enterprise and it could be because tomato production is not labour intensive. Similarly, men might focus more on cash crop production than vegetables. Therefore, this corroborates the result of Abolusoro et al. (2014) which shows that more female was involved in tomato production in Kogi State than males.

\section{Age}

About $36 \%$ of the respondents were between the ages of 41 and 50 years (Table 1), while $20.8 \%$ were within the age range of 51 and 60 years. Furthermore, $20.8 \%$ were aged 31 to 40 years, $11.8 \%$ were 61 years and above and $10.8 \%$ were 21 to 30 years. While the average age of the farmers was 47 years. This indicates that most of the respondents were still active and in their productive age, and could take up innovation, internalize and abide by it. This result agrees with that of Ezeibe et al. (2017) whereby majority of the farmers in Enugu State fell within the range of 41 to 50 years.

\section{Educational Level}

Entries in Table 1 show that about 23\% of the respondents completed secondary school education, $20.0 \%$ primary school, $19.2 \%$ attended tertiary education, $16.7 \%$ of the farmers had no formal education, while $13.3 \%$ and $8.3 \%$ did not complete secondary and primary school. Therefore, majority $(61.7 \%)$ of the respondents were literate and at different levels showing that they could understand simple agronomic practices when taught. According to Oduro-Ofori et al. (2014), education is important in the improvement of agricultural productivity and opens the mind of farmers to knowledge and skills.

\section{Primary Occupation}

As shown in Table 1, majority (78.3\%) of the respondents engaged in farming as their primary occupation, $9.2 \%$ were civil/public servant, $5.0 \%$ were traders, $4.2 \%$ were students, $2.5 \%$ were artisan, and $0.8 \%$ were drivers. The implication of this result that respondents would be well disposed to innovations that aims to improve farming since it was their major source of livelihood. This finding agrees with Sekumade and Toluwase (2014) which stated that a larger percentage 
of tomato farmers in Osun State are highly engaged in farming activities.

Table 1. Socio-economic characteristics of tomato farmers

\begin{tabular}{|c|c|c|c|}
\hline $\begin{array}{l}\text { Socio-economic } \\
\text { characteristics }\end{array}$ & Frequency & $\begin{array}{l}\text { Percentage } \\
(\%)\end{array}$ & $\begin{array}{l}\text { Mean } \\
(\mathrm{M})\end{array}$ \\
\hline \multicolumn{4}{|l|}{ Sex } \\
\hline Male & 39 & 32.5 & \\
\hline Female & 81 & 67.5 & \\
\hline \multicolumn{4}{|l|}{ Age } \\
\hline $21-30$ years & 13 & 10.8 & \\
\hline $31-40$ years & 25 & 20.8 & \\
\hline $41-50$ years & 43 & 35.8 & 47 \\
\hline $51-60$ years & 25 & 20.8 & \\
\hline 61 and above & 14 & 11.8 & \\
\hline \multicolumn{4}{|l|}{ Educational level } \\
\hline No formal education & 20 & 16.7 & \\
\hline $\begin{array}{l}\text { Primary school } \\
\text { attempted }\end{array}$ & 10 & 8.3 & \\
\hline $\begin{array}{l}\text { Primary school } \\
\text { completed }\end{array}$ & 24 & 20.0 & \\
\hline $\begin{array}{l}\text { Secondary school } \\
\text { attempted }\end{array}$ & 16 & 13.3 & \\
\hline $\begin{array}{l}\text { Secondary school } \\
\text { completed }\end{array}$ & 27 & 22.5 & \\
\hline Tertiary education & 23 & 19.2 & \\
\hline \multicolumn{4}{|l|}{$\begin{array}{l}\text { Primary } \\
\text { occupation }\end{array}$} \\
\hline Farming & 94 & 78.3 & \\
\hline Trading & 6 & 5.0 & \\
\hline Civil/public servant & 11 & 9.2 & \\
\hline Artisan & 3 & 2.5 & \\
\hline Driving & 1 & 0.8 & \\
\hline Student & 5 & 4.2 & \\
\hline
\end{tabular}

Similarly, the knowledge and skill level of the farmers were thus given:

\section{Level of Practical Skill on Postharvest Handling}

Majority (84.2\%) of the respondents had moderate skills on postharvest handling (Figure 4). This means that farmers need to be improve their skills in order for them to reduce postharvest losses, while 9.2\% and $6.7 \%$ had low and high skills. Furthermore, poor skills on postharvest handling means that farmers would incur more losses as a result of spoilage. According to Kiaya (2014), food losses are mainly due to lack of technology, insufficient skills, knowledge, and management capacity of farmers. A study conducted by Abimbola (2014) revealed that farmers' gross margin in tomato production reduced from $80 \%$ to $17 \%$ as a result of post- harvest losses.

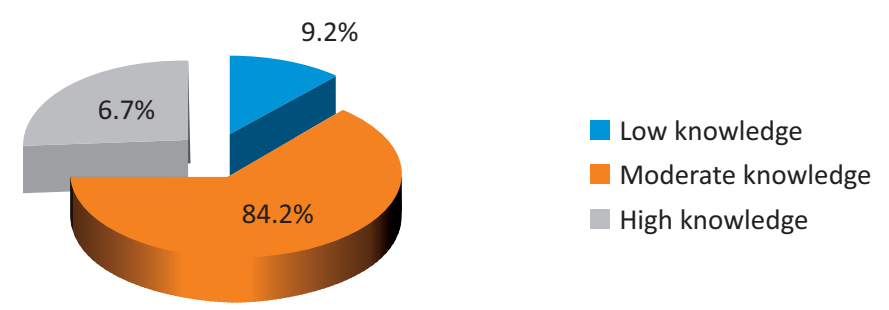

Figure 4. Knowledge level of tomato farmers

The tomato charcoal cooler bin showed that its evaporative cooling rate could support the preservation of fresh and flesh tomatoes as shown in Figure 5. It followed the daily patterns and rose to the peak during the day and reduced as the temperature fell. However, this was different for periods of water recharge on the charcoal cooler bin which occurred at the $11^{\text {th }}$ and $7^{\text {th }}$ hours interval for day 1 , and 2 and 11 hours for day 3 .

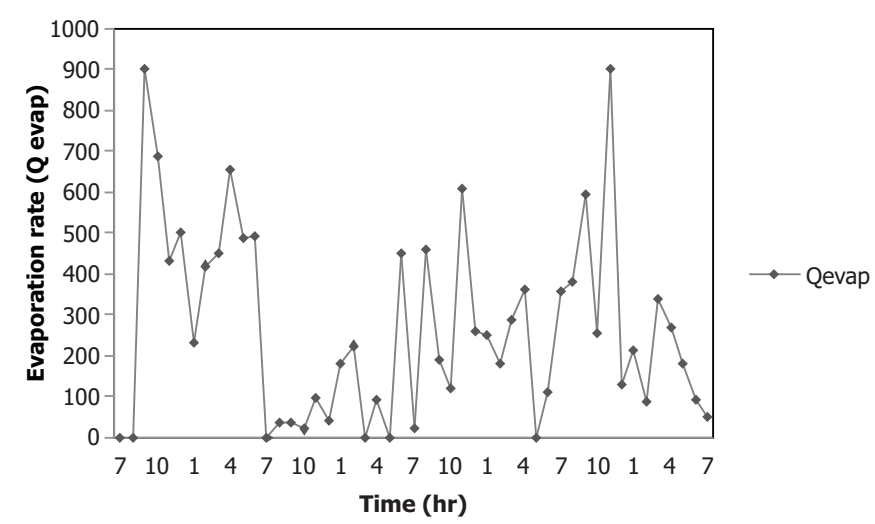

Figure 5. The evaporative cooling rate of the tomato charcoal cooler bin

Based on the study conducted for the six comparative environment storage conditions for preserving and storing flesh and fresh tomatoes in the tropics, Table 3 showed the analysis of variance for the mean of the weight loss percentage for the four tomato varieties. Furthermore, it was also analyzed graphically as shown in Figure 6. 
Table 2. Practical skills of farmers on postharvest handling of tomato

\begin{tabular}{lrr}
\hline Post-harvest skills in tomato production & Freq & Percentage (\%) \\
\hline Harvest tomato manually & 115 & 95.8 \\
Pre-cool tomato after harvesting & 95 & 79.2 \\
Clean and disinfect tomato after harvesting & 66 & 55.0 \\
Sort tomatoes & 112 & 93.3 \\
Grade tomatoes & 102 & 85.0 \\
Sun-dry tomato after harvesting & 112 & 93.3 \\
Preserve tomato using refrigeration & 17 & 14.2 \\
Use ethylene to treat tomato & 8 & 6.7 \\
Preserve tomato using modified atmosphere packaging (MAP) & 7 & 5.8 \\
Preserve tomato using methylcyclopropene (1-MCP) & 4 & 3.3 \\
Preserve tomato using calcium chloride (CaCl $)$ application (Chlorine) & 5.8 \\
Protect tomato from insect/pest infestation & 7 & 40.8 \\
Pick tomato from the plant without bruise & 49 & 75.0 \\
Pack tomato without any mechanical damage & 90 & 75.0 \\
Protect tomato from disease & 90 & 54.2 \\
Make a shade where you spread tomato for ventilation & 65 & 62.5 \\
Preserve tomato using charcoal & 75 & 16.7 \\
Treat tomato using heated water (blanching) & 20 & 14.2 \\
Store tomato under room temperature & 17 & 56.7 \\
\hline
\end{tabular}

Field survey, 2019.

Based on the fresh tomatoes storage behaviour, the mean weight loss percentage depicted that freezer showed lowest weight loss followed by refrigerator, charcoal cooler, and thatched house storages. Furthermore, open-air and laboratory storages witnessed significant weight losses because it was under the influence of environmental temperature and relative humidity of the tropics. This was graphically ascertained under 5\% HSD where weight losses and time were determinants. Similarly, according to Tadesse et al. (2015), it showed that at $4^{\circ} \mathrm{C}$ storage of tomato, weight loss was inhibited but at $20^{\circ} \mathrm{C}$ and $30^{\circ} \mathrm{C}$ it was $(p<0.05)$ significantly enhanced.

Similarly, the refractometric records in determining the brix value as well as ascertain the rate of spoilage or deterioration in terms of total soluble solid in the tomato varieties was presented in the Table 4 and graphically shown in Figure 7.

It was found that total soluble solid values of the local fresh tomatoes were such that charcoal cooler, open-air, room (laboratory) and hatch house storages maintained the Total Soluble Solid of the tomato which was above 4.5 brix value but were low compared to

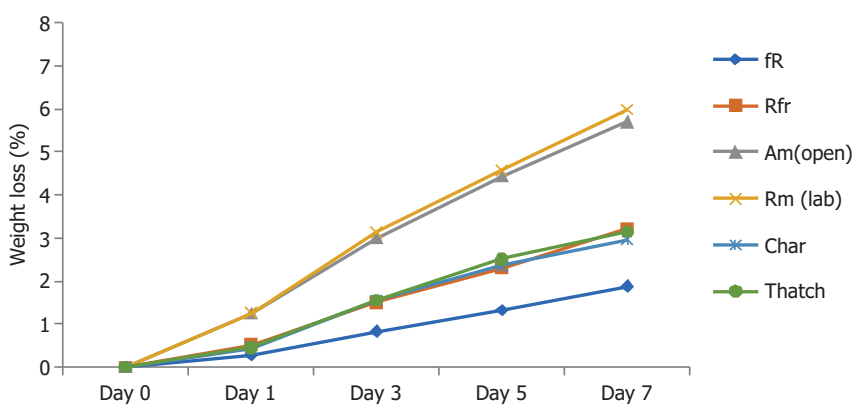

Figure 6. Weight Loss percentages of local fresh tomatoes stored in different environmental conditions with time

the other three storage media. Furthermore, the digital camera captured the daily ripening and deterioration of the tomato under storage. Figure 6 showed the effect of different storage medium on tomato (yolings) preservation at $7^{\text {th }}$ day of storage. However, open air and room (laboratory) storage had shown some deterioration (rupture and watering), while freezer, refrigerator, thatched house, and charcoal cooler bin was moderately slow in deterioration with tendency. 
Table 3. Weight loss percentage of four tomato varieties

\begin{tabular}{cllcccc}
\hline Replication & $\begin{array}{c}\text { Storage } \\
\text { systems } \\
\text { (treatment) }\end{array}$ & $\begin{array}{c}\text { Day 0 } \\
(\%)\end{array}$ & $\begin{array}{c}\text { Day } 1 \\
(\%)\end{array}$ & $\begin{array}{c}\text { Day 3 } \\
(\%)\end{array}$ & $\begin{array}{c}\text { Day 5 } \\
(\%)\end{array}$ & $\begin{array}{c}\text { Day 7 } \\
(\%)\end{array}$ \\
\hline 1 & Fr & $0.00 \pm 0.00$ & $0.16 \pm 0.01$ & $0.67 \pm 0.01$ & $1.17 \pm 0.01$ & $1.64 \pm 0.01$ \\
1 & Rfr & $0.00 \pm 0.00$ & $0.47 \pm 0.01$ & $1.31 \pm 0.01$ & $2.04 \pm 0.01$ & $2.87 \pm 0.01$ \\
1 & Am (open) & $0.00 \pm 0.00$ & $1.20 \pm 0.01$ & $2.97 \pm 0.01$ & $4.33 \pm 0.01$ & $5.65 \pm 0.01$ \\
1 & Rm (Lab) & $0.00 \pm 0.00$ & $1.20 \pm 0.00$ & $2.92 \pm 0.01$ & $4.31 \pm 0.01$ & $5.58 \pm 0.01$ \\
1 & Char & $0.00 \pm 0.00$ & $0.41 \pm 0.00$ & $1.47 \pm 0.00$ & $2.32 \pm 0.00$ & $2.93 \pm 0.00$ \\
1 & Thatch & $0.00 \pm 0.00$ & $0.49 \pm 0.01$ & $1.66 \pm 0.00$ & $2.59 \pm 0.01$ & $3.25 \pm 0.00$ \\
2 & Fr & $0.00 \pm 0.00$ & $0.43 \pm 0.00$ & $0.99 \pm 0.00$ & $1.48 \pm 0.00$ & $2.12 \pm 0.00$ \\
2 & Rfr & $0.00 \pm 0.00$ & $0.58 \pm 0.01$ & $1.69 \pm 0.01$ & $2.58 \pm 0.00$ & $3.59 \pm 0.00$ \\
2 & Am (Open) & $0.00 \pm 0.00$ & $1.33 \pm 0.02$ & $3.30 \pm 0.01$ & $4.83 \pm 0.04$ & $6.33 \pm 0.10$ \\
2 & Rm (Lab) & $0.00 \pm 0.00$ & $1.30 \pm 0.00$ & $3.09 \pm 0.01$ & $4.56 \pm 0.01$ & $5.83 \pm 0.02$ \\
2 & Char & $0.00 \pm 0.00$ & $0.40 \pm 0.01$ & $1.46 \pm 0.01$ & $2.14 \pm 0.01$ & $2.70 \pm 0.01$ \\
2 & Thatch & $0.00 \pm 0.00$ & $0.50 \pm 0.01$ & $1.66 \pm 0.01$ & $2.70 \pm 0.01$ & $3.36 \pm 0.02$ \\
\hline
\end{tabular}

Table 4. Analysis of variance for refractometric test

\begin{tabular}{lccc}
\hline \multicolumn{1}{c}{ Treatment } & Brix value & STDEV & CV (\%) \\
\hline FR & 5.95 & 0.06 & 0.01 \\
Rfr & 5.63 & 0.40 & 0.07 \\
Am (open) & 5.38 & 0.56 & 0.10 \\
Rm (lab) & 5.13 & 0.10 & 0.02 \\
Char & 5.20 & 0.54 & 0.10 \\
Thatch & 5.44 & 0.33 & 0.06 \\
\hline
\end{tabular}

Table 5. Analysis of variance for firmness test

\begin{tabular}{lccc}
\hline \multicolumn{1}{c}{ Treatment } & $\begin{array}{c}\text { Firmness } \\
\text { average }\end{array}$ & C.V (\%) & 5\% HSD \\
\hline FR & 0.87 & 1.9 & $\mathrm{a}$ \\
Rfr & 0.81 & 3.7 & $\mathrm{ab}$ \\
Am (open) & 0.59 & 12.4 & $\mathrm{C}$ \\
Rm (Lab) & 0.79 & 2.1 & $\mathrm{~b}$ \\
Char & 0.81 & 1.3 & $\mathrm{ab}$ \\
Thatch & 0.81 & 2.5 & $\mathrm{ab}$ \\
\hline
\end{tabular}

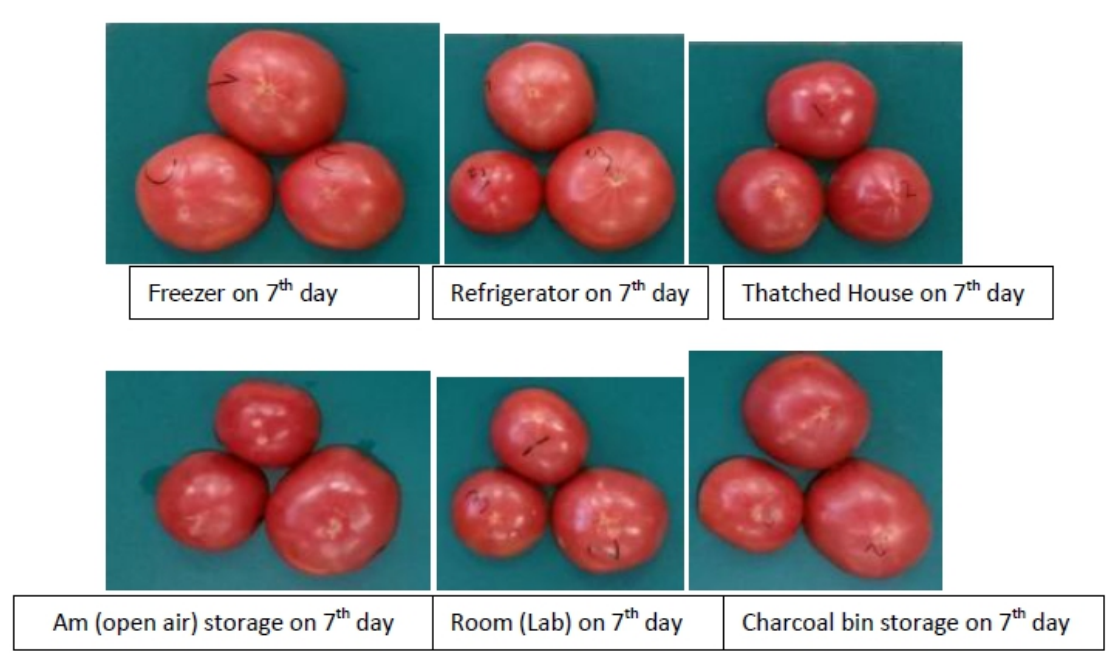

Figure 7. Effect of different storage medium on flesh Tomato (yolings) preservation on $7^{\text {th }}$ day 


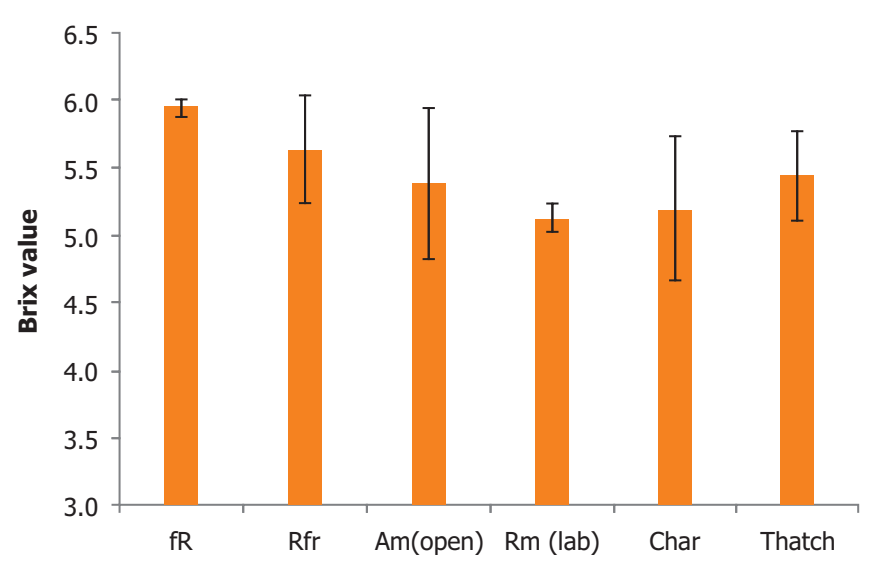

Figure 8. Total soluble solids value of fresh tomatoes under storage conditions

The total soluble solid (TSS) of the local tomatoes was maintained on these storage media with variations as shown in Figure 8 (Tadesse et al., 2015). Furthermore, the flesh and fresh tomato firmness was determined as shown in Figure 9.

The firmness of the tomato was analyzed based on the analysis of variance as shown in Table 5 . Furthermore, freezer storage was showing above normal characteristic, while refrigerator, Charcoal cooler bin and thatched house were showing the same effect in terms of firmness. Furthermore, open air and room storage were showing different levels of firmness (softening) at different rate.

Based on the graph below, firmness test showed that freezer storage had better performance, followed by refrigerator, charcoal cooler, and thatch house storages. Furthermore, room and open air storages had low performance. Tomatoes stored on freezer had freezing stress and such had delayed loss in TSS and also room and open air storage were under the influence of temperature and relative humidity (Tadesse et al., 2015).

\section{CONCLUSION}

Based on the results obtained, it was concluded that Majority of the tomato farmers were females with an average age of 47 years. They were literate as well as being a tomato farmer by occupation with a moderate level of practical skills on postharvest handling of tomatoes. $57.7 \%$ of the farmers stored the produce under room temperature and were willing to accept innovative ideas for handling and storing tomatoes. Different storage media for tomato preservation were studied and also the flesh and fresh quality attributes

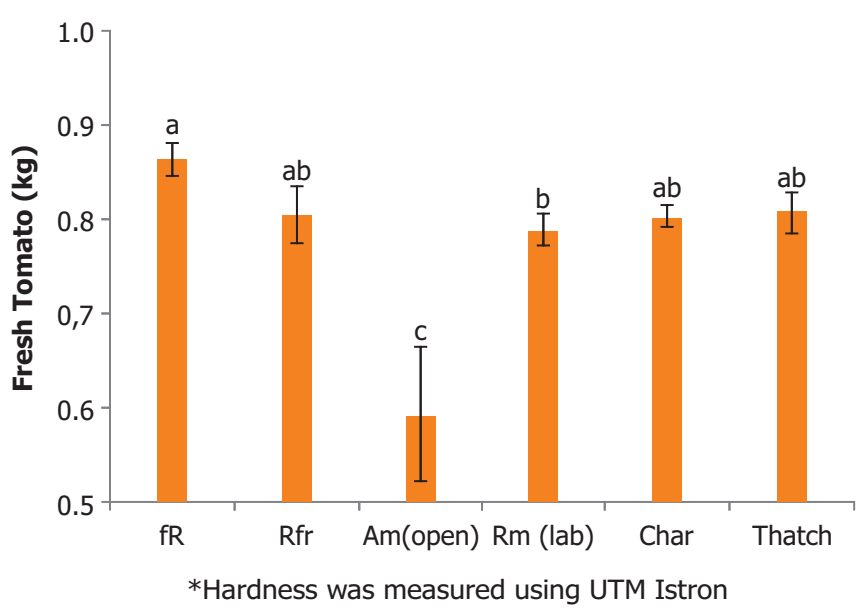

Figure 9. Hardness of fresh tomato fruits on $7^{\text {th }}$ day of storage

were measured. Furthermore, the results showed it had different behaviours under storage. Freezer and refrigerator storages showed good performance, and this was followed closely by tomato charcoal cooler bin and thatched house storage. Furthermore, low performance was seen on open-air and room storages. This promoted the use of tomato charcoal bin storage in low income countries in terms of affordability, accessibility, portable, user-friendly and less operational cost, standalone and performance. It is an appropriate technology for flesh and fresh tomato storage in the tropics for small scale farmers with limited resources. Therefore, the use of tomato charcoal cooler storage bin need to be encouraged since it is regarded as a local refrigerator.

\section{ACKNOWLEDGEMENT}

The authors are grateful to their instructor at JICA training 2018 in Tsukuba, Japan.

\section{CONFLICT OF INTEREST}

There was no conflict of interest on this work.

\section{REFERENCES}

Abimbola, O. (2014). Postharvest losses and welfare of tomato farmers in Ogbomosho, Osun state, Nigeria. Journal of Stored Products and Postharvest Research, 5 8-13 10.5897/JSPPR2014.0160.

Abolusoro P. F., Ogunjimi S. I., and Abulosoro S. A. (2014). Farmers' perception on the strategies for increasing 
tomato production in Kabba-Bunu Local Government Area of Kogi State, Nigeria. Agrosearch, 14(2), 144-153.

Arah, K. I, Kumah, E. K. Anku, E. K., and Amaglo, H. (2015). An overview of postharvest losses in tomato production in Africa: causes and possible prevention strategies. Journal of Biology, Agriculture and Healthcare, 5(16), 78-88.

Ezeibe, A. B. C, Okonkwo, N. A, Opata, P. I. Dennis, O. E., and Diogu, A. N. (2017). Analysis of entrepreneurship development in agriculture among female groundnut farmers in Enugu state. European Journal of Business and Management, 9(32).

FAO/World Bank Work (2010). Reducing postharvest losses in grain supply chains in Africa: lessons learned and practical guidelines. FAO/World Bank Work FAO Headquarters 18-19 Rome, Italy.

Food and Agricultural Organisation (FAO) (2008). Basic harvest and postharvest handling considerations for fresh fruits and vegetables handling and preservation, FAO, Rome, Italy, 2008.

Food and Agricultural Organisation Statistic FAOSTAT (2013). Global tomato production in 2013, FAO, Rome, Italy
Kiaya, V. (2014). Postharvest losses and strategies to reduce them. Action Contre La Faim (ACF). Retrieved from http://www.academia.edu/download/45278162/post harvest_losses.pdf

Oduro-Ofori E., Aboagye, A. P., and Acquaye N. A. E. (2014). Effects of education on the agricultural productivity of farmers in the offinso municipality. International Journal of Development Research, 4(9), 19511960.

Odesola, I. F. and O. Onyebuchi. (2009). A review of porous evaporative cooling for the preservation of fruits and vegetables. Pacific Journal of Science and Technology. 10(2):935- 941.

Sekumade A.B and Toluwase S.O.W. (2014). Profitability and production efficiency of indigenous tomato cultivation among farmers in Osun State, Nigeria. Journal of Agriculture and Veterinary Science, (IOSR-JAVS), 7(11), 13-23

Tadesse, T. N., Ali, M. I., and Wosene G. A., (2015) Degradation and formation of fruit color in tomato (Solanum lycopersicum L.) in response to storage temperature. American Journal of Food Technology, 10: 147-157. Doi: 10.3923/ajft.2015.147.157 